\title{
BEHAVIOR OF A MINUTE AMOUNT OF FURFURAL IN DISTILLATION OF AOUEOUS ETHANOL SOLUTION UNDER REDUCED PRESSURE
}

\author{
Atsushi IKARI, Yasuo HATATE, SeIICHI SAKAUE \\ AND YUKINORI KUBOTA \\ Department of Chemical Engineering, Kagoshima University, Kagoshima 890
}

Key Words: Distillation, Vacuum, Vapor-Liquid Equilibrium, Trace Component, Plate Efficiency, Ethanol, Furfural

\begin{abstract}
To clarify the behavior of a trace component during distillation under reduced pressure, the vapor-liquid equilibrium ratio and the plate efficiency of the trace component are needed.

Vapor-liquid equilibria of aqueous ethanol solution containing about $0.05 \mathrm{wt} \%$ furfural (trace component) were measured at $25.3 \mathrm{kPa}$ and $12.7 \mathrm{kPa}$ by use of an Othmer-type still. The equilibrium ratio of furfural varys only slightly with the reduction of pressure.

Distillation experiments were carried out by use of an Oldershow-type column at atmospheric pressure, $25.3 \mathrm{kPa}$ and $12.7 \mathrm{kPa}$. A method for calculating the plate efficiency from the concentrations of distillate and bottoms was derived. The calculated results show that the Murphree vapor efficiency is little affected by pressure in the range of $12.7 \mathrm{kPa}$ to atmospheric pressure.

By reducing the pressures, the bubble point of the system decreases remarkably, but the change of behavior of a trace component in distillation becomes quite small.
\end{abstract}

\section{Introduction}

To investigate the behavior of a trace component in distillation, the vapor-liquid equilibrium and the plate efficiency of the trace component are required. For the last decade several studies on these problems have been carried out by the authors. ${ }^{1-8)}$ They, however, have been confined to distillation at atmospheric pressure. The behavior of a trace component in distillation under reduced pressure has not been reported up to this time.

In this study aqueous ethanol solutions containing a minute amount of furfural were used. Furfural is known as a representative trace impurity encountered in liquor production.

The vapor-liquid equilibria were measured by use of an Othmer-type still with a reduced pressure control system. The equilibrium ratios of furfural were obtained at $25.3 \mathrm{kPa}$ and $12.7 \mathrm{kPa}$. Distillation experiments were carried out at atmospheric pressure, $25.3 \mathrm{kPa}$ and $12.7 \mathrm{kPa}$ by use of an Older show-type column.

A simple mathematical model employing Murphree vapor efficiency as an adjustable parameter was derived. The efficiency of the trace component was obtained from the experimental concentrations of

Received September 13, 1983. Correspondence concerning this article should be addressed to A. Ikari. S. Sakaue is now with Nippon Sanso Co., Ltd., Tokyo 105. Y Kubota is now with Sanko Engineering \& Construction Co., Ltd., Yokohama 230. distillate and bottoms.

The effect of pressure on the equilibrium ratio as well as the Murphree vapor efficiency (abbreviated EMV) of the trace component is discussed.

\section{Vapor-Liquid Equilibrium}

\subsection{Experiment}

For the measurement of vapor-liquid equilibrium, an Othmer-type still with a reduced pressure control system was used. A schematic diagram of the experimental apparatus is shown in Fig. 1. The pressure in the apparatus was maintained substantially constant by use of a needle valve and a buffer tank of about 20 liters.

An aqueous ethanol solution containing about $0.05 \mathrm{wt} \%$ furfural was charged in the still. The apparatus was operated for about 7 hours under the desired pressure. After the vacuum pump was stopped and the pressure was returned to atmospheric pressure, samples for both phases were withdrawn for analysis.

The density of the sample was measured at $25^{\circ} \mathrm{C}$ and the concentration of ethanol was determined from the density curve. The concentration of furfural was determined by spectrophotometry. After dilution of the sample with water, the absorbance of the peak at about $277 \mathrm{~nm}$ was measured and the concentration of furfural was determined with the calibration curve. 


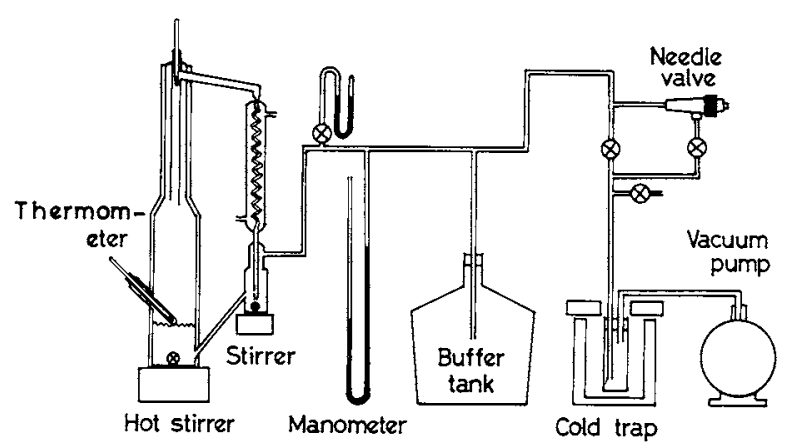

Fig. 1. Schematic diagram of apparatus for vapor-liquid equilibrium measurements.

\subsection{Results and discussion}

The results of vapor-liquid equilibrium measurements are shown in Figs. 2 and $\mathbf{3}$.

Figure 2 shows the vapor-liquid equilibrium relation of the major components, water and ethanol. The co-ordinates of this figure, $x_{2}^{\prime}$ and $y_{2}^{\prime}$, are respectively the mole fraction of ethanol in liquid and vapor phase, on a trace component free basis:

$$
x_{2}^{\prime}=x_{2} /\left(x_{1}+x_{2}\right) \text { and } y_{2}^{\prime}=y_{2} /\left(y_{1}+y_{2}\right) .
$$

These $x_{2}^{\prime}-y_{2}^{\prime}$ curves were compared with $x_{2}-y_{2}$ curves obtained from the binary data ${ }^{10)}$ of the waterethanol system at the same pressure. Both curves are substantially coincident. It can be found that the vapor-liquid composition curve of the major components is only slightly affected by the reduction of pressure.

The equilibrium ratio of the trace component $\left(\equiv y_{3} / x_{3}\right)$ is plotted against $x_{2}^{\prime}$ in Fig. 3 , in which the data ${ }^{9)}$ at atmospheric pressure are also plotted for comparison. The curves at $25.3 \mathrm{kPa}$ and $12.7 \mathrm{kPa}$ show nearly identical results and are located slightly above the curve at atmospheric pressure. The effect of pressure on the equilibrium ratio of furfural appears to be relatively small.

On the contrary, the bubble point is affected remarkably by the reduction of pressure. In the case of $50 \mathrm{~mol}^{\%}$ ethanol solution, the bubble point changes from $80^{\circ} \mathrm{C}$ at $101.3 \mathrm{kPa}$ to about $50^{\circ} \mathrm{C}$ at $25.3 \mathrm{kPa}$ and $36^{\circ} \mathrm{C}$ at $12.7 \mathrm{kPa}$.

\section{Distillation Experiments}

\subsection{Apparatus and procedure}

Distillation experiments were carried out by use of a ten-stage Oldershow-type column, $50 \mathrm{~mm}$ in diameter by $45 \mathrm{~mm}$ tray spacing, with vacuum jacket. A schematic diagram of the apparatus is shown in Fig. 4. The apparatus was connected with the same reduced pressure control system as shown in Fig. 1. The still consisted of a 1-liter flask with three necks, in one of which a capillary tube was mounted to prevent bumping. Thermocouples for temperature measure-

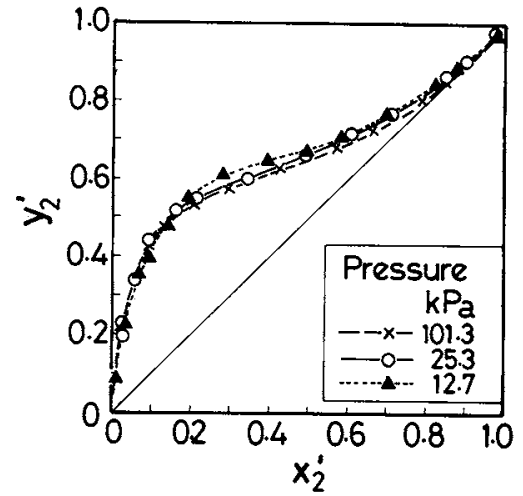

Fig. 2. Vapor-liquid composition curves of the major component (water-ethanol).

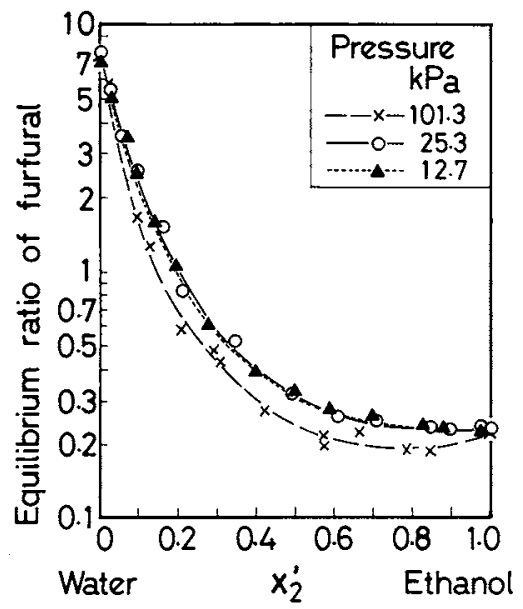

Fig. 3. Equilibrium ratio curves of the trace component (furfural).

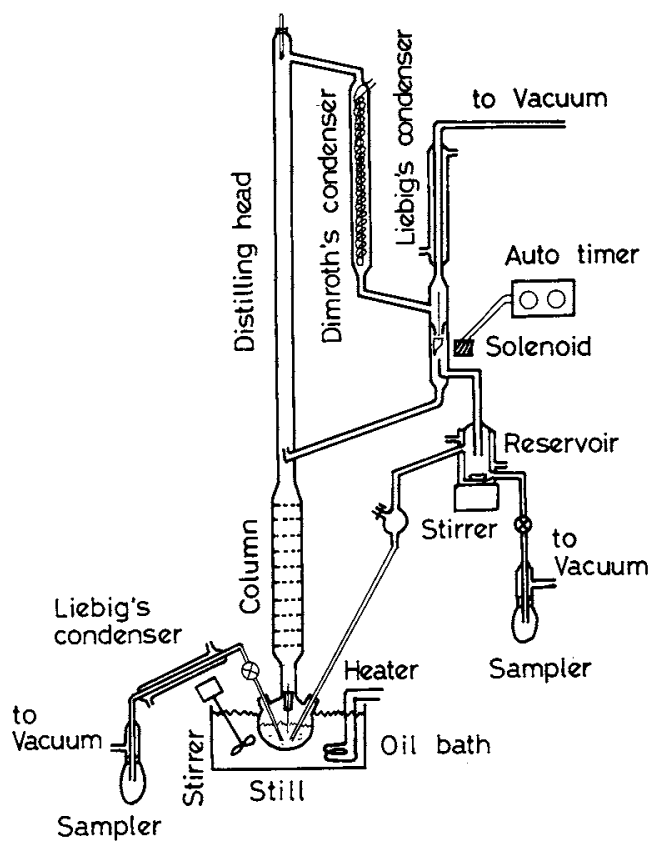

Fig. 4. Schematic diagram of apparatus for distillation experiments. 
ment were located at six points.

A feed solution of the specified concentration was charged in the still. Under a desired pressure the apparatus was operated for 3 to 6 hours according to the vapor rate until steady state. Samples were withdrawn from the reservoir and the still. They were analysed by the same method as stated in the previous section.

\subsection{Experimental results}

The experimental conditions and results of the first series of experiments are shown in Table 1. To reveal the effect of pressure and the vapor rate, these runs were carried out at a constant reflux ratio $(=8)$ and at nearly constant feed compositions.

In the next section we determine the EMV of the trace component by using the experimentally obtained concentrations in distillate and bottoms. In these calculations we need the ethanol concentration in the liquid on each plate in the column, because the equilibrium ratio of the trace component is a function of ethanol concentration. It is assumed that the ethanol concentrations are obtained by the distillation calculation, as will be mentioned in the next section.

The error inherent in the calculated ethanol concentration may cause some error in the determination of EMV of the trace component. To eliminate the error an azeotropic mixture of water and ethanol containing a minute amount of furfural was used as a feed solution in the second series of experiments. The experimental conditions and results of this series are shown in Table 2.

\section{Calculation of Plate Efficiency}

\subsection{Derivation of equations}

A schematic model of our distillation experiments is shown in Fig. 5.

The following assumptions have been made.

(1) The condenser is a total condenser.

(2) The conditions of constant molal overflow are applied.

(3) The EMV of the major component and that of the trace component are each assigned a constant value throughout the column.

(4) The efficiencies at still are unity.

(5) The presence of a trace component does not affect the equilibrium relation of only the major component.

(6) The equilibrium ratio of a trace component is a function of the concentration of the major component, but is independent of the concentration of the trace component.

From the equilibrium relation $\left(y_{n}^{*}=K_{n} x_{n}\right)$ and the definition of EMV, the following equation is derived.

$$
y_{n}=E K_{n} x_{n}+(1-E) y_{n+1}
$$

Assumptions (1) and (4) yield, respectively,

$$
\begin{aligned}
y_{1} & =x_{D}=x_{0} \\
y_{N+1} & =K_{N+1} x_{N+1}
\end{aligned}
$$

Material balances around the bottom and an arbitrary plate $n(1<n \leqslant N)$ result in, respectively,

$$
\begin{gathered}
x_{N}=(V / L) y_{N+1}-(D / L) x_{D} \\
x_{n-1}=x_{n}+(V / L)\left(y_{n}-y_{n+1}\right)
\end{gathered}
$$

Here, Eq. (1) through Eq. (5) hold for any component, but only two of the EMV's are independent of each other.

To determine EMV from the experimentally obtained concentrations of distillate $\left(x_{D}\right)$ and bottoms $\left(x_{N+1}\right)$, the following procedure was used. Initially, the value of $E$ is assumed. By use of Eqs. (3), (4), (5) and (1), plate-to-plate calculation is perform from the bottom to the top plate. If the calculated value of $y_{1}$ does not agree with $x_{D}$ within the tolerance, the value of $E$ is adjusted and the calculations are iterated.

For the first series of experiments in Table 1, the calculation procedure was adopted first for ethanol among the major components and second for the trace component.

For the second series of experiments in Table 2, the calculation procedure was adopted only for the trace component, because the ethanol concentration was almost unchanged on all plates in the column and the equilibrium ratio of furfural was regarded as constant in this ethanol concentration range, as shown in Fig. 3.

\subsection{Results and discussion}

The calculated values of EMV are included in the last columns of Tables 1 and 2 .

In experiments No. 5 to 12 in Table 2, the samples were withdrawn after the pressure was returned to atmospheric pressure. The concentration of furfural in the bottoms was corrected for the liquid on the plates fallen into the bottom by use of the liquid holdup on the plates, which had been determined as about $10 \%$ of the liquid in the column. By this correction the EMV of furfural became about $1.8 \%$ greater (maximum $2.7 \%$ ).

The values of EMV in Table 1 are plotted in Fig. 6, which shows that EMV is not affected by the vapor rate when the vapor rate becomes larger than about $30 \mathrm{~g} \cdot \mathrm{cm}^{-2} \cdot \mathrm{h}^{-1}$. No effect of pressure on the EMV of ethanol can be observed. The EMV of furfural is recognized to become lower by the reduction of pressure, but the effect is not so large.

A typical diagram of the calculated concentration profiles in the column is shown in Fig. 7. In the lower part of the column, the concentration of ethanol decreases rapidly and accordingly the concentration of furfural represents a peak. 
Table 1. Experimental results of distillation for the water-ethanol-furfural system at constant reflux ratio $(=8)$ and constant feed composition

\begin{tabular}{|c|c|c|c|c|c|c|c|c|c|}
\hline \multirow{2}{*}{$\begin{array}{l}\text { Exp. } \\
\text { No. }\end{array}$} & \multirow{2}{*}{$\begin{array}{c}\text { Vapor } \\
\text { rate } \\
{\left[\mathrm{g} \cdot \mathrm{cm}^{-2} \cdot \mathrm{h}^{-1}\right]}\end{array}$} & \multicolumn{2}{|c|}{$\begin{array}{l}\text { Composition in } \\
\text { feed }\left[\mathrm{mol}_{\%} \text { ] }\right.\end{array}$} & \multicolumn{2}{|c|}{$\begin{array}{l}\text { Composition in } \\
\text { distillate }[\mathrm{mol} \%]\end{array}$} & \multicolumn{2}{|c|}{$\begin{array}{l}\text { Composition in } \\
\text { bottoms }[\mathrm{mol} \%]\end{array}$} & \multicolumn{2}{|c|}{$\begin{array}{l}\text { Murphree vapor } \\
\text { efficiency }[-]\end{array}$} \\
\hline & & Ethanol & Furfural & Ethanol & Furfural & Ethanol & Furfural & Ethanol & Furfural \\
\hline \multicolumn{10}{|c|}{ Pressure $=$ atmospheric pressure } \\
\hline 1 . & 24.5 & 11.61 & 0.0221 & 83.24 & $4.27 \times 10^{-5}$ & 4.93 & 0.0235 & 0.816 & 0.714 \\
\hline 2 & 24.8 & 11.61 & 0.0221 & 83.86 & $4.89 \times 10^{-5}$ & 5.06 & 0.0231 & 0.884 & 0.698 \\
\hline 3 & 28.4 & 11.61 & 0.0220 & 84.07 & $4.30 \times 10^{-5}$ & 4.48 & 0,0225 & 0.942 & 0.726 \\
\hline \multicolumn{10}{|c|}{ Pressure $=25.3 \mathrm{kPa}$} \\
\hline 4 & 17.1 & 11.86 & 0.0228 & 84.70 & $4.65 \times 10^{-5}$ & 6.36 & 0.0229 & 0.855 & 0.744 \\
\hline 5 & 29.4 & 11.93 & 0.0223 & 83.86 & $1.27 \times 10^{-4}$ & 5.66 & 0.0229 & 0.804 & 0.690 \\
\hline 6 & 51.6 & 11.87 & 0.0226 & 83.86 & $1.58 \times 10^{-4}$ & 5.85 & 0.0230 & 0.802 & 0.670 \\
\hline 7 & 59.7 & 11.92 & 0.0222 & 83.45 & $1.70 \times 10^{-4}$ & 5.52 & 0.0217 & 0.780 & 0.668 \\
\hline 8 & 94.7 & 11.63 & 0.0217 & 84.07 & $2.14 \times 10^{-4}$ & 5.25 & 0.0218 & 0.822 & 0.655 \\
\hline \multicolumn{10}{|c|}{ Pressure $=12.7 \mathrm{kPa}$} \\
\hline 9 & 15.9 & 11.78 & $0.0225^{1}$ & 84.91 & $1.89 \times 10^{-4}$ & 5.75 & 0.0226 & 0.840 & 0.669 \\
\hline 10 & 28.0 & 11.85 & 0.0221 & 84.70 & $3.89 \times 10^{-4}$ & 5.71 & 0.0222 & 0.822 & 0.610 \\
\hline 11 & 39.3 & 11.79 & 0.0219 & 84.28 & $4.19 \times 10^{-4}$ & 5.06 & 0.0215 & 0.794 & 0.618 \\
\hline 12 & 68.7 & 11.86 & 0.0219 & 85.12 & $4.75 \times 10^{-4}$ & 5.34 & 0.0218 & 0.863 & 0.604 \\
\hline
\end{tabular}

Table 2. Experimental results of distillation for the water-ethanol-furfural system of azeotropic feed mixture (water-ethanol)

\begin{tabular}{|c|c|c|c|c|c|c|c|c|c|}
\hline \multirow{2}{*}{$\begin{array}{l}\text { Exp. } \\
\text { No. }\end{array}$} & \multirow{2}{*}{$\begin{array}{c}\text { Reflux } \\
\text { ratio } \\
{[-]}\end{array}$} & \multirow{2}{*}{$\begin{array}{c}\text { Vapor } \\
\text { rate } \\
{\left[\mathrm{g} \cdot \mathrm{cm}^{-2} \cdot \mathrm{h}^{-1}\right]}\end{array}$} & \multicolumn{2}{|c|}{$\begin{array}{l}\text { Composition in } \\
\text { feed }\left[\mathrm{mol}^{\circ} \mathrm{c}\right]\end{array}$} & \multicolumn{2}{|c|}{$\begin{array}{l}\text { Composition in } \\
\text { distillate }[\mathrm{mol} \%]\end{array}$} & \multicolumn{2}{|c|}{$\begin{array}{l}\text { Composition in } \\
\text { bottoms }\left[\mathrm{mol}^{\circ} \%\right.\end{array}$} & \multirow{2}{*}{$\begin{array}{l}\text { Murphree vapor } \\
\text { efficiency of } \\
\text { furfural }[-]\end{array}$} \\
\hline & & & Ethanol & Furfural & Ethanol & Furfural & Ethanol & Furfural & \\
\hline \multicolumn{10}{|c|}{ Pressure $=$ atmospheric pressure } \\
\hline 1 & 8 & 24.7 & 88.32 & 0.0456 & 89.25 & $4.26 \times 10^{-5}$ & 87.85 & 0.0783 & 0.574 \\
\hline 2 & 4 & 26.5 & 88.32 & 0.0456 & 89.02 & $3.96 \times 10^{-5}$ & 88.08 & 0.0688 & 0.584 \\
\hline 3 & 2 & 27.6 & 89.88 & 0.0460 & 89.68 & $4.76 \times 10^{-5}$ & 89.41 & 0.0676 & 0.599 \\
\hline 4 & 1 & 25.8 & 89.88 & 0.0461 & 89.92 & $6.30 \times 10^{-5}$ & 89.63 & 0.0692 & 0.645 \\
\hline \multicolumn{10}{|c|}{ Pressure $=25.3 \mathrm{kPa}$} \\
\hline 5 & 8 & 51.4 & 90.56 & 0.0462 & 91.97 & $4.50 \times 10^{-5}$ & 90.09 & 0.0618 & 0.594 \\
\hline 6 & 4 & 50.6 & 90.56 & 0.0462 & 91.74 & $5.56 \times 10^{-5}$ & 90.09 & 0.0581 & 0.591 \\
\hline 7 & 2 & 29.8 & 90.78 & 0.0464 & 91.74 & $4.44 \times 10^{-5}$ & 90.56 & 0.0470 & 0.634 \\
\hline 8 & 1 & 27.5 & 90.78 & 0.0463 & 91.28 & $1.08 \times 10^{-5}$ & 90.55 & 0.0482 & 0.642 \\
\hline \multicolumn{10}{|c|}{ Pressure $=12.7 \mathrm{kPa}$} \\
\hline 9 & 8 & 43.5 & 91.01 & 0.0463 & 92.90 & $4.25 \times 10^{-5}$ & 90.33 & 0.0470 & 0.579 \\
\hline 10 & 4 & 29.1 & 91.01 & 0.0464 & 92.67 & $4.46 \times 10^{-5}$ & 90.55 & 0.0494 & 0.599 \\
\hline 11 & 2 & 30.0 & 91.01 & 0.0464 & 91.97 & $6.11 \times 10^{-5}$ & 90.54 & 0.0606 & 0.634 \\
\hline 12 & 1 & 38.5 & 91.01 & 0.0464 & 91.74 & $1.20 \times 10^{-4}$ & 90.78 & 0.0484 & 0.645 \\
\hline
\end{tabular}

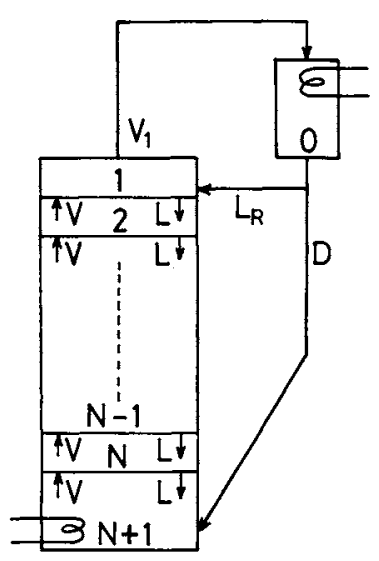

Fig. 5. Model of distillation experiment.

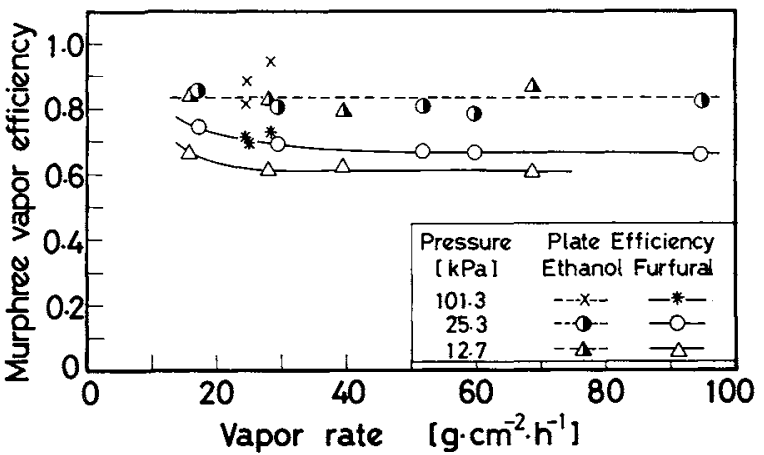

Fig. 6. Murphree vapor efficiencies obtained from the experiments in Table 1. 

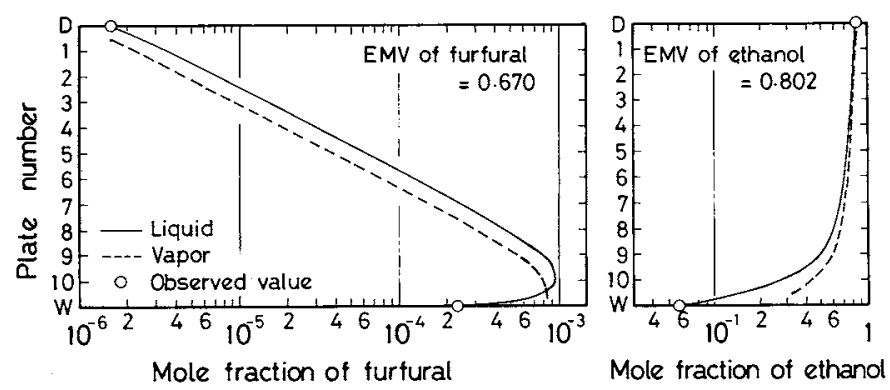

Fig. 7. Calculated concentration profiles in the column (Exp. No. 6 in Table 1).

The values of EMV in Table 2 are plotted in Fig. 8, which shows that the EMV of furfural in the azeotropic solution of ethanol and water is not affected by the reduction of pressure. The EMV increases slightly as the reflux ratio decreases. The interpretation of this increase is difficult and is left to further examination.

A typical diagram of the calculated concentration profiles in the column is shown in Fig. 9, in which the EMV of furfural varies linearly in contrast to that in Fig. 7.

The differences of EMV of furfural in Table 2 (Fig. 8) with that in Table 1 (Fig. 6) seem to be attributable to the decrease of ethanol concentration in the lower part of the column shown in Fig. 7, because it is noted in the previous paper ${ }^{8)}$ that the EMV of furfural increases as the ethanol concentration decreases.

\section{Conclusion}

Vapor-liquid equilibria of aqueous ethanol solutions containing a minute amount of furfural were measured at $25.3 \mathrm{kPa}$ and $12.7 \mathrm{kPa}$. When the pressure is reduced, the bubble point decreases remarkably, but the equilibrium ratio curve of the trace component does not vary significantly.

Distillation experiments were carried out by use of an Oldershow-type column at atmospheric pressure, $25.3 \mathrm{kPa}$ and $12.7 \mathrm{kPa}$. The Murphree vapor efficiency of the trace component was determined from the experimental concentrations of distillate and bottoms.

It is shown that the efficiency of the trace component is little affected by pressure in the range of $12.7 \mathrm{kPa}$ to atmospheric pressure.

\section{Acknowledgment}

The financial assistance of the Grant-in-Aid for Scientific Research of the Ministry of Education, Japan (No. 56550675) is gratefully acknowledged.

\section{Nomenclature}

$D \quad=$ distillate rate (returned to the bottom)

$E \quad=$ Murphree vapor efficiency

$K=$ equilibrium ratio

$L \quad=$ liquid rate in the column

$V \quad=$ vapor rate in the column

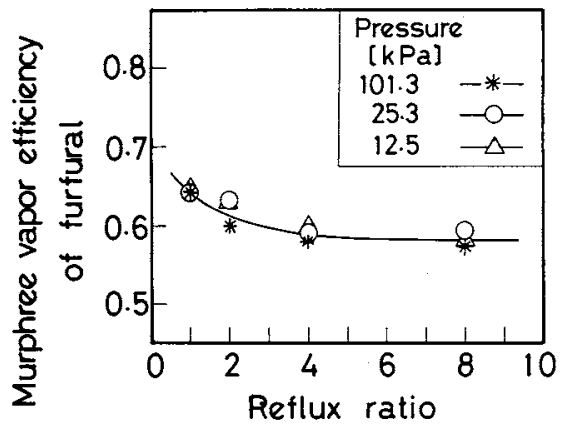

Fig. 8. Murphree vapor efficiencies obtained from the experiments in Table 2 .

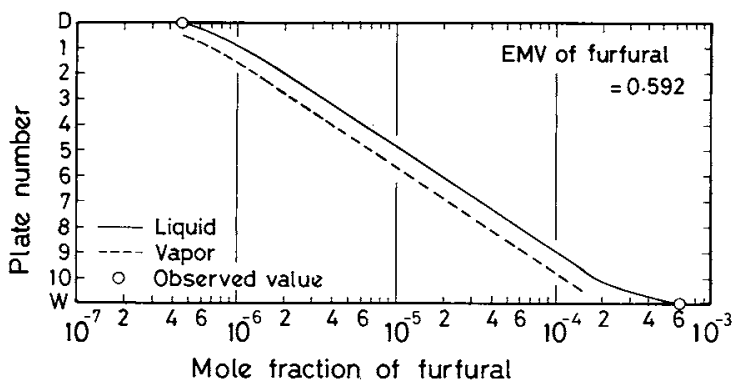

Fig. 9. Calculated concentration profiles in the column (Exp. No. 6 in Table 2).

$$
\begin{array}{ll}
x & =\text { mole fraction in liquid } \\
y & =\text { mole fraction in vapor } \\
y^{*} & =y \text { in equilibrium with } x \\
\langle\text { Subscripts }\rangle & \\
D & =\text { distillate } \\
N & =\text { number of plates } \\
n & =\text { plate number } \\
1 & =\text { water } \\
2 & =\text { ethanol } \\
3 & =\text { furfural (trace component) }
\end{array}
$$

\section{Literature Cited}

1) Ikari, A., S. Mishima and I. Otsubo: J. Chem. Eng. Japan, 7(4), 271 (1974).

2) Ikari, A. and R. Kubo: J. Chem. Eng. Japan, 8(4), 294 (1975).

3) Ikari, A., Y. Hatate and R. Deguchi: J. Chem. Eng. Japan, 11(4), 265 (1978).

4) Ikari, A. and Y. Hatate: Kagaku Kogaku Ronbunshu, 6(1), 23 (1980).

5) Ikari, A., Y. Hatate and K. Tanaka: J. Chem. Eng. Japan, 13(2), 87 (1980):

6) Ikari, A., Y. Hatate and K. Tanaka: Reserach Reports of Faculty of Eng. Kagoshima Univ., 22, 167 (1980).

7) Ikari, A., Y. Hatate and T. Gotoh: Rep. Asahi Glass Found. Ind. Technol., 38, 289 (1981).

8) Ikari, A., Y. Hatate and R. Kabayama: Rep. Asahi Glass Found. Ind. Technol., 38, 295 (1981).

9) Ikari, A. and S. Toyo: Kagaku Kōgaku, 35, 1131 (1971).

10) Kogan, V. B. (translated by M. Hirata): "Kiekiheiko Data Book," p. 248, Kodansha (1974).

(Presented at Fukuoka Meeting of The Society of Chemical Engineers, Japan (Fukuoka) on July 14, 1983.) 